\title{
Availability Verification of Effluent from BFT Inland Aquaculture for Urban Agricultural Fertilizer through Cherry Tomato Cultivation
}

\author{
Yong Hyun Kim ${ }^{1,2}$, Moo Ryong Huh ${ }^{1,2} *$, Jeong Ho Lee ${ }^{3}$, Young Sik Lee ${ }^{3}$, and Hye Sung Choi ${ }^{4}$ \\ 1 Department of Horticulture, Gyeongsang National University, Jinju 52828, South Korea \\ ${ }^{2}$ Institute of Agriculture \& Life Science, Gyeongsang National University, Jinju 52828, South Korea \\ ${ }^{3}$ Inland Aquaculture Research Center, National Institute of Fisheries Science, Jinhae 51691, South Korea \\ ${ }^{4}$ Southwest Sea Fisheries Research Institute, National Institute of Fisheries Science, Yeosu 59780, South Korea
}

\begin{abstract}
As the interest in urban agriculture and people's demand for eco-friendly food grow, the number of urban gardeners who directly grow and harvest will increase. The aim of this study was to compare the effect of conventional fertilizer with the effluent water from the biofloc technology inland aquaculture in the concept of resource circulation as a substitute for fertilizer used in urban agriculture. In order to verify the effect of fertilizer on the cultivation of cherry tomato, tomato seedlings were transplanted on the horticultural soil without nutrients and treated for 8 weeks. Experimental treatment was carried out in five treatments: control, hyponex solution (HS), slow-released fertilizer (SF), effluent water daily treatment (DE), and effluent water treatment once a week (WE). The growth characteristics of the cherry tomatoes showed significant differences among the treatments except for root length. In the case of plant length was shown $\mathrm{HS}=\mathrm{WE}>\mathrm{DE}=\mathrm{SF}>$ control, and stem diameter was shown $\mathrm{DE}=\mathrm{SF}$ $>W E=H S>$ control. It was found that $\mathrm{HS}$ and WE were not significantly different in shoot length and diameter, and DE and SF showed no difference. In the case of number of leaves, HS, DE, and WE showed a significantly higher level than SF and control. In other growth characteristics, DE and SF showed higher growth.

As for the growth of cherry tomato fruit, the sugar content did not show any significant difference among the treatments except control. Weight per fruit and yield were significantly higher in HS and WE than DE and SF. Based on these results, it is considered that the use of effluent water is comparable to the use of urban agricultural fertilizer as compared with chemical fertilizers in cultivating crops.
\end{abstract}

Keywords: alternative fertilizer, kitchen garden, recycling effluent water, resource virtuous cycle, urban farming

\section{Introduction}

Since the liberation, South Korea has been facing rapid concentration of population in the city due to modernization, resulting in urban expansion to a broad extent even to the agricultural areas near the suburbs (Kwon, 2014). The Ministry of Land, Infrastructure, and Transport announced that $91 \%$ of the population in Korea lives in the city (MLIT, 2015), and as a result of such modernization and urbanization, agriculture began to disappear in the city. However, it made a comeback into the city during World War as vegetables began to be cultivated on little pieces of land as a means to resolve

This study was funded by the "Development of Fish Biofloc Farming Technology (BFT) (R2016019)" by the National Fisheries Research \& Development Institute.

Received: July 26, 2017, Revised: August 3, 2017, Accepted: August 7, 2017

*Comesponding author: mrhuh@gnu.ac.kr 
the food shortage issue in the city, and the form of agriculture called urban agriculture worldwide began to take root (Hong, 2012; Kim, 2015). In South Korea, the Agricultural Technology Center of Seoul began to promote weekend farms with the slogan "Agriculture with Citizens" in 1992, and the Act on Development and Support of Urban Agriculture began to take effect in 2012, currently resulting in the trend of urban agriculture along with institutional support (Kwon, 2014).

Along with policy and institutional support to promote urban agriculture, many people are tending urban vegetable gardens for self-sufficiency of food and pursuit of health in raising safe foods without chemical fertilizers or pesticides among various functions of urban agriculture (Lee and Cho, 2016). Accordingly, as many people have come to have more and more interest in organic agricultural products, they are tending urban vegetable gardens using various organic compounds to replace chemical fertilizers (Kim et al., 2011), and studies have been conducted on all kinds of organic fertilizers using coffee byproducts, sea mustard culturing byproducts or other similar marine algae or fish, microorganisms of fresh herbs, or byproducts after cultivating tomatoes as substitutes for chemical fertilizers (Cho, 2015; Illera-Vives et al., 2015; Kim, 2016; Park, 2015). There are many cases in which manure from livestock excretions is used along with organic fertilizers with the goal of eco-friendly cultivation (Park, 2016). According to Zhou et al. (2005), livestock excretions are rich in organic matters like nitrogen and phosphorus, having a positive effect on the growth of crops as well as on improving the physical properties of soil.

According to the research findings that composting of aquaculture effluents as agricultural recycling includes many organic matters such as nitrogen and phosphorus in the fish excretions (Kim et al., 2016a), aquaculture effluent perceived as a water pollution source (Lee, 2001; Subramaniam et al., 1994) can be used as a concept of a virtuous cycle of resources. The aquaculture effluent used in this study was discharged from a farm that applied biofloc technology (BFT), which is an eco-friendly farming technique that reduces water pollution by removing excess organic nitrogen in fish excretions and remaining fertilizers using biofloc in the water treatment process of the farm (Cho et al., 2015). In particular, effluents from inland water culture applying BFT contain organic nitrogen or phosphorus necessary for plant growth, and thus can be used as a useful resource in cultivating crops (Kim et al., 2016a).

Therefore, this study determines the effects of aquaculture effluents as a fertilizer using cherry tomatoes as well as conventional liquid fertilizers and slow-release fertilizers on soil, through which it explores the possibility of using effluents from BFT inland aquacultures as fertilizer for urban agriculture and agricultural recycling.

\section{Research Method}

\section{Materials and method of experiment}

The cultivation experiment was conducted for total 8 weeks from April 15 to June 8, 2016 at a greenhouse in G University located in Jinju, Gyeongsangnam-do. For the material, cherry tomatoes Lycopersicon esculentum 'Minichal' raised at $\mathrm{C}$ nursery in the same city were purchased, planting on plastic no. 8 pot with a diameter of $20 \mathrm{~m}$ with horticultural bed soil Tosili without fertilizer ingredients. When planted on April 15, 2016, the tomatoes had an average plant length of $22.3 \mathrm{~cm}$, average stem of $4.7 \mathrm{~mm}$, and chlorophyll content SPAD of 45.5, and 7.8 leaves, showing no interplant significance as a result of statistical analysis. The experiment was set up and conducted as shown in Table 1 according to the randomized complete block design with three replications of three plants for each treatment. Treatment consisted of total 5 types: control plot, Hyponex solution (HS), daily effluent water (DE), weekly effluent water (WE), and slow-release fertilizer (SF). The effluents used in the experiment were collected every week from the inland water farm of the National Fisheries Research \& Development Institute located in Jinhae-gu, Changwon, Gyeongnam. $300 \mathrm{ml}$ of water was drenched every day in the case of the control plot, and $300 \mathrm{ml}$ of Hyponex (Hyponex high grade, Hyponex inc,, Japan) 
Table 1. Experimental treatment method of nutrient solutions from effluent fertilizer for urban farming at cherry tomato cultivation.

\begin{tabular}{ll}
\hline \multicolumn{1}{c}{ Treatment } & \multicolumn{1}{c}{ Method } \\
\hline Control & Water $300 \mathrm{ml}$ every day \\
$\mathrm{HS}$ & Water $300 \mathrm{ml} 5$ times a week + hyponex solution $300 \mathrm{ml} 1$ time per week \\
$\mathrm{DE}$ & Effluent water from biofloc system $300 \mathrm{ml}$ every day \\
$\mathrm{WE}$ & Water $300 \mathrm{ml}$ from biofloc system 5 times a week + effluent water $300 \mathrm{ml} 1$ time per week \\
$\mathrm{SF}$ & First time fertilization $20 \mathrm{~g}+$ water $300 \mathrm{ml}$ every day \\
\hline
\end{tabular}

$\mathrm{HS}=500$ diluted time hyponex solution; $\mathrm{DE}=$ Daily effluent water from biofloc system; $\mathrm{WE}=$ Weekly effluent water from biofloc system; $\mathrm{SF}=$ Slow-release fertilizer.

500x was drenched once a week for HS and $300 \mathrm{ml}$ of water was drenched aside from this, while $300 \mathrm{ml}$ of an undiluted solution of effluent was drenched every day for DE. As for WE, $300 \mathrm{ml}$ of an undiluted solution of effluent was drenched once a week. For SF, $20 \mathrm{~g}$ of Danhanbeon fertilizer (Chobi co. Ltd., Korea) (N:P:K=18:7:9) that is slow-release fertilizer was top-dressed on each pot after planting, after which $300 \mathrm{ml}$ of water was drenched every day.

\section{Growth examination and component analysis}

Growth examination was carried out on June 8, 2016, which was Week 8 after planting. Measurement items included growth characteristics of crops such as plant length, root length, stem diameter, number of leaves, chlorophyll content, fresh weight, and dry weight. Fruit characteristics as harvests include measurements of sugar content, fruit stalk and fruit weight, and content analysis of lycopene that is the functional matter in fruits. For items related to total fruit harvests, the number and weight of harvests were measured by separately classifying fruits that are red-ripe when harvested for the last time. Root length of crops and fruit stalks of fruits were measured using digital vernier calipers (Absolute Digimatic 500-182, MItutoyo Co., Japan), and chlorophyll content was measured using Minolta SPAD 502 (SPAD502, Minolta, Japan). As for fresh weight, all fruits and flower clusters formed after the first harvest were removed, after which the aboveground and underground parts were separated for analysis. Dry weight was measured after measuring the fresh weight and drying the flowers for 3 days in a $70^{\circ} \mathrm{C}$ dry oven. Sugar content of the fruit was measured using an automatic saccharimeter (Pocket refractometer PAL-1, Atago, Japan), and lycopene that is the functional matter in the fruit was quantified by calculating the chromatogram area using HPLC.

\section{Statistical analysis}

The measured data are organized with Microsoft Office Excel, and statistics program SAS 9.4 was used to conduct one-way ANOVA with the confidence level of 95\% and Duncan's multiple range test, through which significance test among averages in each treatment was conducted.

\section{Results and Discussions}

\section{Crop growth characteristics}

As a result of determining the usability of aquaculture effluents as urban agriculture fertilizer by cultivating cherry tomatoes, it was found that plant length showed significantly highest value in HS and WE plots, whereas root length 
showed no significant difference in all plots. Stem diameter showed greatest growth in DE and SF, and the number of leaves also showed excellent growth in 3 plots except for the control plot and SF (Table 2). As for SPAD that measures chlorophyll content in the plant body, there was no big difference in all plots except for the control plot. This result was similar to that of Kim et al. (2016b) who conducted an experiment on cultivating eggplants, which also belong to solanaceae, using aquaculture effluents. It was also similar to Kim et al. (2013) who cultivated cherry tomatoes using manure filtered liquefied fertilizer filtered after spraying pig manure slurry on manure like chaff and sawdust, and also to Ryoo and Seo (2008) who cultivated tomatoes using pig manure concentrate fertilizer. Fresh weight of the aboveground part was highest in SF, followed by WE and DE, but there was no significant difference among plots treated with effluents. On the contrary, fresh weight of the underground part was highest in DE and WE, followed by SF and HS. Dry weight turned out to be high in DE for both aboveground and underground parts. The aboveground dry weight was significantly highest in DE unlike the aboveground fresh weight, followed by SF, WE, HS and control plot. The underground dry weight showed a significant difference of being highest in DE, followed by WE, HS and SF, but there was no significant difference among the treated plots. The result of crop growth shows that in cultivating cherry tomatoes, using aquaculture effluents will compare favorably as urban agriculture fertilizer with conventional Hyponex or slow-release solid fertilizer commonly used.

\section{Fruit growth characteristics}

\section{Individual fruit growth characteristics}

As a result of investigating fruit characteristics of cherry tomatoes harvested using aquaculture effluents, conventionally

Table 2. Growth characteristics of cherry tomatoes by fertigation with different nutrient solution treatments.

\begin{tabular}{|c|c|c|c|c|c|c|}
\hline Treatment & $\begin{array}{l}\text { Plant height } \\
\quad(\mathrm{cm})\end{array}$ & \multicolumn{2}{|c|}{$\begin{array}{l}\text { Length of the longest root } \\
\qquad(\mathrm{cm})\end{array}$} & $\begin{array}{l}\text { Stem diameter } \\
(\mathrm{mm})\end{array}$ & \multicolumn{2}{|c|}{$\begin{array}{l}\text { No. of leaves } \\
\text { (ea) }\end{array}$} \\
\hline Control & $64.03 c^{z}$ & \multicolumn{2}{|c|}{$52.72 \mathrm{a}$} & $6.62 \mathrm{c}$ & \multicolumn{2}{|c|}{$10.11 \mathrm{c}$} \\
\hline HS & $144.78 \mathrm{a}$ & \multicolumn{2}{|c|}{$56.89 \mathrm{a}$} & $7.43 b$ & \multicolumn{2}{|c|}{$23.56 \mathrm{a}$} \\
\hline $\mathrm{DE}$ & $122.26 b$ & \multicolumn{2}{|c|}{$55.33 \mathrm{a}$} & $8.95 \mathrm{a}$ & \multicolumn{2}{|c|}{$23.67 \mathrm{a}$} \\
\hline WE & $141.89 a$ & \multicolumn{2}{|c|}{$50.33 \mathrm{a}$} & $7.80 \mathrm{~b}$ & \multicolumn{2}{|c|}{$23.67 \mathrm{a}$} \\
\hline SF & $118.54 b$ & \multicolumn{2}{|c|}{$52.00 \mathrm{a}$} & $8.77 \mathrm{a}$ & \multicolumn{2}{|c|}{$18.56 \mathrm{~b}$} \\
\hline Significance & $* * *$ & \multicolumn{2}{|c|}{ NS } & $* * *$ & \multicolumn{2}{|c|}{$* * *$} \\
\hline \multirow{2}{*}{ Treatment } & \multirow{2}{*}{$\mathrm{T} / \mathrm{R}$ ratio } & \multirow{2}{*}{$\begin{array}{l}\text { Chloropyll content } \\
\text { (SPAD) }\end{array}$} & \multicolumn{2}{|c|}{ Fresh weight (g) } & \multicolumn{2}{|c|}{ Dry weight (g) } \\
\hline & & & Shoot & Root & Shoot & Root \\
\hline Control & $2.29 c^{z}$ & $24.50 \mathrm{~b}$ & $30.97 d$ & $13.70 \mathrm{c}$ & $5.56 \mathrm{~d}$ & $0.69 \mathrm{c}$ \\
\hline HS & $6.13 b$ & $63.53 \mathrm{a}$ & $122.43 c$ & $24.37 \mathrm{~b}$ & $20.02 \mathrm{c}$ & $1.43 \mathrm{~b}$ \\
\hline $\mathrm{DE}$ & $5.57 \mathrm{~b}$ & $61.67 \mathrm{a}$ & $161.33 b$ & $29.68 \mathrm{a}$ & $26.76 \mathrm{a}$ & $2.24 \mathrm{a}$ \\
\hline WE & $5.29 \mathrm{~b}$ & $63.66 \mathrm{a}$ & $154.78 b$ & $29.62 \mathrm{a}$ & $24.38 b$ & $1.48 \mathrm{~b}$ \\
\hline SF & $6.89 \mathrm{a}$ & $68.28 \mathrm{a}$ & $182.51 \mathrm{a}$ & 27.81ab & $24.73 \mathrm{ab}$ & $1.16 \mathrm{~b}$ \\
\hline Significance & $* * *$ & $* * *$ & $* * *$ & $* * *$ & $* * *$ & $* * *$ \\
\hline
\end{tabular}

$\mathrm{HS}=500$ diluted time hyponex solution; $\mathrm{DE}=$ Daily effluent water from biofloc system; WE=Weekly effluent water from biofloc system; $\mathrm{SF}=$ Slow-release fertilizer.

${ }^{\mathrm{z}}$ Mean separation within columns of each treatment by Duncan's multiple range test at $p=.05$. 
used liquid fertilizers and slow-release fertilizers, there was no significance difference in fruit sugar content among treated plots except for the control plot, but the order was SF $\left(9.56^{\circ} \mathrm{Brix}\right)$, DE $\left(9.28^{\circ} \mathrm{Brix}\right)$, WE $\left(8.96^{\circ} \mathrm{Brix}\right)$, and $\mathrm{HS}\left(8.93^{\circ} \mathrm{Brix}\right)$ (Table 3). The species 'Minichal' used in the experiment is a species of cherry tomatoes with high sugar content of 9 10 Brix on average (Park, 2014), and the result of the experiment showed that using aquaculture effluents showed not much of a difference compared to generally cultivated crops in farmhouses. Fruit size was significantly biggest in HS and control plot, followed by WE, DE and SF. The average weight of each fruit was highest in HS, followed by WE, control plot, DE and SF. However, there was no statistically significant difference between HS and WE, and DE and SF. This was similar to the result of An et al. (2016) reporting that there was no statistical difference in cucumber weight between fish meal nutrients and chemical fertilizers. According to these results, the size of the fruit itself is small in DE and SF, but there was effect on forming a fruit with high sugar content. Functional matter lycopene in cherry tomatoes (Fig. 1) tended to increase by 1.7 times in DE and 1.4 times in WE compared to the control plot, and DE showed a 1.3 times increase compared to HS. This result was similar to Kim et al. (2016b) reporting that there was high content of functional matters in crops cultivated using aquaculture effluents.

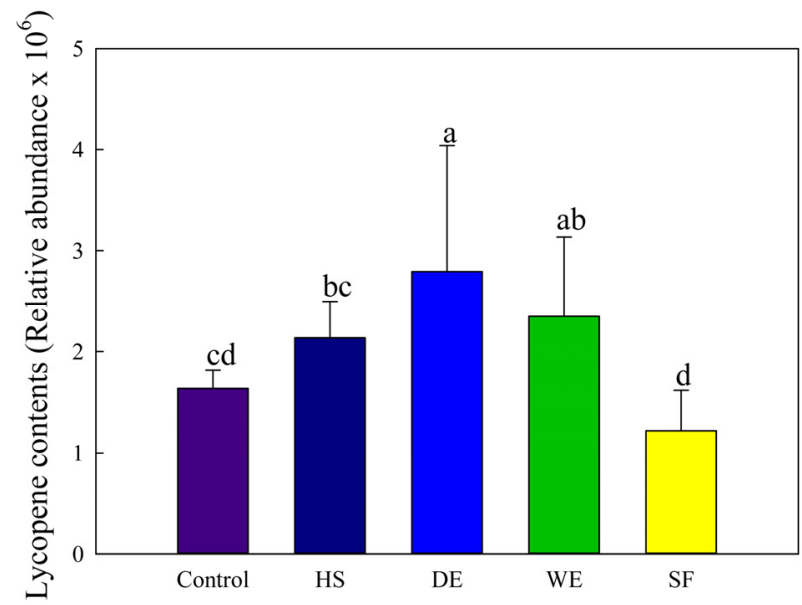

Figure 1. Cherry tomato lycopene contents by different nutrient solution treaments. $\mathrm{HS}=500$ diluted time hyponex solution; $\mathrm{DE}=$ Daily effluent water; $\mathrm{WE}=$ Weekly effluent water; $S F=S l o w$-release fertilizer. Bars with the same letter are not significantly different at the $5 \%$ level based on Duncan's Multiple Range Test.

Table 3. Cherry tomato production parameters: soluble solid content, fruit size (caliber and weight) by different nutrient solution treatments.

\begin{tabular}{lccc}
\hline \multirow{2}{*}{ Treatment } & $\begin{array}{c}\text { Soluble solid content } \\
(\text { Brix })\end{array}$ & $\begin{array}{c}\text { Fruit diameter } \\
(\mathrm{mm})\end{array}$ & $\begin{array}{c}\text { Fruit weight } \\
(\mathrm{g} / \mathrm{ea})\end{array}$ \\
\hline Control & $8.34 \mathrm{~b}^{\mathrm{z}}$ & $24.89 \mathrm{a}$ & $10.70 \mathrm{~b}$ \\
$\mathrm{HS}$ & $8.93 \mathrm{a}$ & $25.45 \mathrm{a}$ & $11.58 \mathrm{a}$ \\
$\mathrm{DE}$ & $9.28 \mathrm{a}$ & $23.97 \mathrm{~b}$ & $9.57 \mathrm{c}$ \\
$\mathrm{WE}$ & $8.96 \mathrm{a}$ & $24.75 \mathrm{ab}$ & $11.07 \mathrm{ab}$ \\
$\mathrm{SF}$ & $9.56 \mathrm{a}$ & $23.08 \mathrm{c}$ & $9.45 \mathrm{c}$ \\
\hline Significance & $* *$ & $* * *$ & $* * *$ \\
\hline
\end{tabular}

$\mathrm{HS}=500$ diluted time hyponex solution; $\mathrm{DE}=$ Daily effluent water; $\mathrm{WE}=$ Weekly effluent water; $\mathrm{SF}=$ Slow-release fertilizer.

${ }^{\mathrm{z}}$ Mean separation within columns of each treatment by Duncan's multiple range test at $p=.05$. 


\section{Total fruit production characteristics}

Total number of cherry tomatoes harvested was biggest in HS (42.78 \pm 5.12$)$ and WE (39.22 \pm 3.46$)$, and the two had no

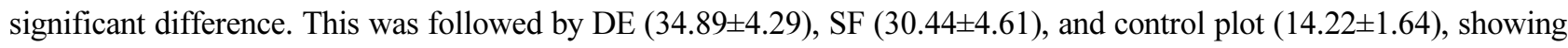
statistically significant result for each treatment (Fig. 2A). The total amount of harvest per treatment (g) (Fig. 2B) showed a similar result with the number of harvests, showing the biggest amount in WE (271.71 \pm 39.28$)$ followed by HS (268.83 \pm 37.68$)$, but not showing a significant difference. As for DE (206.96 \pm 10.39$)$ and SF (215.19 \pm 40.28$)$, amount of production was slightly bigger in slow-release fertilizers unlike the number of harvests. This result was similar to Park et al. (2010) reporting that the quantity of tomatoes was smaller in pig excreata liquefied fertilizers than chemical fertilizers. The reason for this result is that initial growth was good in when using pig excreata liquefied fertilizers and tended to show overgrowth, thereby resulting in smaller fruit number. The result of this study also implies that output may have been smaller in DE due to similar reasons. Accordingly, using WE on fruit production may not be a big problem as fertilizer for urban vegetable gardens compared to using HS, and this result is similar to Illera-Vives et al. (2015) claiming that tomato output increased after using organic fertilizers from sea algae and fish by-products though they were not aquaculture effluents, and also to An et al. (2016) claiming that there was no statistical difference in fruit weight and quantity for each treatment for cucumber growth according to liquefied fertilizers from fish meal and chemical fertilizers. Furthermore, it was also similar to Lim et al. (2013) reporting the replaceability of chemical fertilizers using livestock excretions in the standard of the amount of applied fertilizer for soil test in cucumber fertigation using livestock excretion liquefied fertilizers. Accordingly, using effluents from BFT inland aquacultures as fertilizer has value like other organic fertilizers or livestock excretions.

\section{Conclusion}

The increasing interest in urban agriculture and demand for eco-friendly food cultivation led to a growing number of urban vegetable garden users where they can cultivate and harvest their own foods. In particular, the level of environmental perception improved among people in creating urban vegetable gardens, which resulted in the increase of organic cultivation. Studies are being conducted on organic cultivation using various by-products such as livestock excretions or used coffee grounds rich in organic matters instead of chemical fertilizers in cultivating crops. This study conducted an
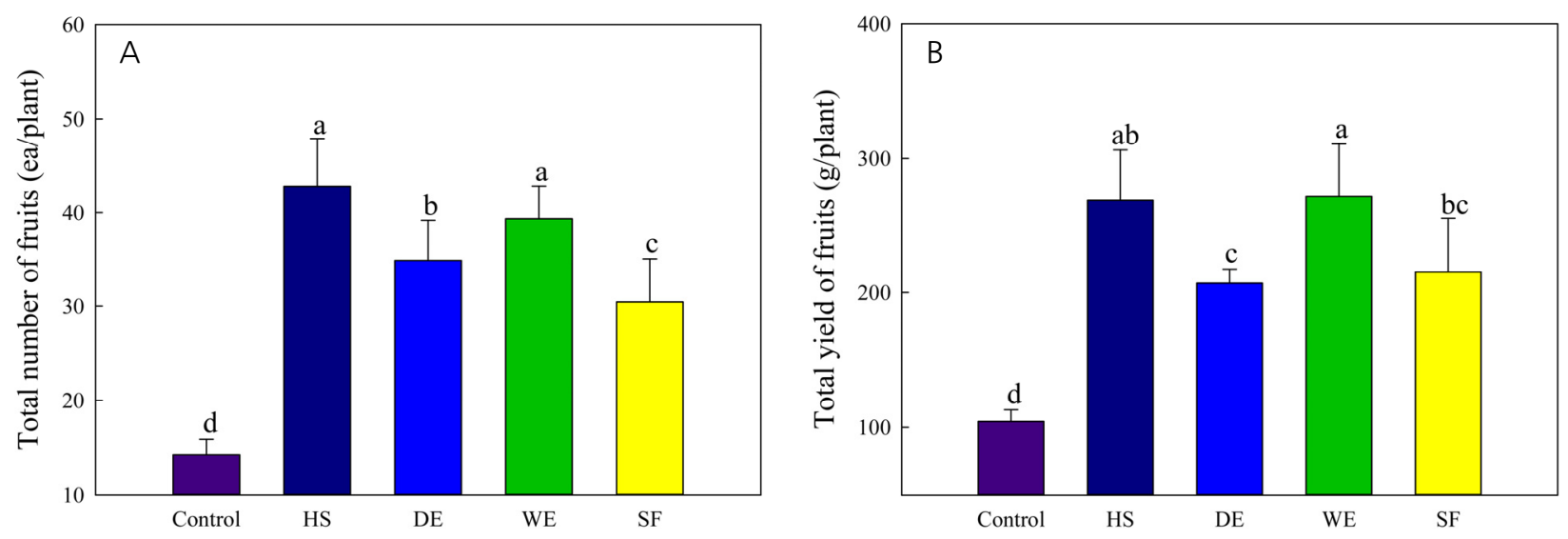

Figure 2. Cherry tomato production parameters per plant by different nutrient solution treaments. $A=$ Total number of fruits; $B=$ Total yield of fruits. $\mathrm{HS}=500$ diluted time hyponex solution; $\mathrm{DE}=$ Daily effluent water; $\mathrm{WE}=\mathrm{Weekly}$ effluent water; SF=Slow-release fertilizer. Bars with the same letter are not significantly different at the $5 \%$ level based on Duncan's Multiple Range Test. 
experiment on cultivating cherry tomatoes using aquaculture effluents perceived as a water pollution source in order to assess the usability as urban agriculture fertilizer for organic cultivation. In vegetative growth of cherry tomatoes, fertilization of aquaculture effluents led to relatively good growth in plots that used the effluents compared to liquefied fertilizers or slow-release fertilizers that are used conventionally. Moreover, using aquaculture effluents did not show much difference in sugar content compared to conventional fertilizers or SF for the fruit of cherry tomatoes, but there was some effect on the increase of functional matter lycopene content. Furthermore, using aquaculture effluents once a week showed similar output with HS in terms of total fruit production. This result implied that there is sufficient usability of aquaculture effluents to cultivate crops, just like other organic fertilizers such as livestock excretions or various byproducts. However, the limitation of this study is that the components may not be fixed and consistent due to various matters and different fish type such as fish feed residues or antibiotics in aquaculture effluents. These differences may lead to different results from this study when a different aquaculture effluent is used, which raises the need for follow-up research on the quantity of organic components in effluents. Since this study was an experiment to determine the fertilizer effect, there is a need for empirical experiment of using the fertilizers on urban vegetable gardens for cultivation.

\section{References}

An N.H., J.R. Cho, J.S. Gu, and S.C. Kim. 2016. Comparison of physico-chemical properties of organic liquid fertilizer containing fish meal according to manufacture method. J. Korea Organic Resources Recycling Association 24(3):91-99. DOI: $10.17137 /$ korrae.2016.24.3.91

Cho, S.H., J.H. Jeong, M.H. Kim, K.T. Lee, D.J. Kim, K.H. Kim, S.P. Oh, and C.H. Han. 2015. The effects of temperature on maintaining the stability of water quality in biofloc-based zero-water exchange culture tanks. J. Life Sci. 25(5): 496-506.

Cho, Y.S. 2015. Effect of application amount of liquid fertilizer produed from tomato residue on the fruit growth and composition of organic tomatoes. MS thesis, Chungnam National Univ., Daejeon, Korea.

Hong, C.S. 2012. An analysis on determinants and characteristics of weekend farm participants. MS thesis, Seoul National Univ., Seoul, Korea.

Illera-Vives, M., S.S.Labandeira, L. M. Brito, A. López-Fabal, and M.E. López-Mosquera. 2015. Evaluation of compost from seaweed and fish waste as a fertilizer for horticultural use. Scientia Horticulturae 186:101-107. DOI: 10.1016/ j.scienta.2015.02.008

Kim, E.Y., B.J. Park, and M.M. Oh. 2013. Availability of slurry composting and biofiltration for cultivation of cultivation of cherry tomato. Protected Hort. Plant Factory 22(4):385-391. DOI: 10.12791/KSBEC.2013.22.4.385

Kim, H.S. 2016. A study on effect of horticultural crops growth by mixing ratios of coffee residuce compost. PhD Diss., Hansei Univ., Gunpo, Korea.

Kim, H.S., Y.N. Kim, J.W. Kim, and K.H. Kim. 2011. Properties and heavy metal contents of urban agricultural soils in Seoul. Korean J. Soil Sci. Fert. 44(6):1045-1051.

Kim, M.Y. 2015. Analysis for crop cultivation and its decisive factors in urban farming -Focusing on Anyang and Gwacheon in Korea-. MS thesis, Univ. Seoul, Seoul, Korea.

Kim, Y.H., S.G. Sohn, Y.S. Lee, H.S. Choi, and M.R. Huh. 2016a. Development of urban agricultural fertilizer of effluent water from BFT inland aquaculture. J. Korean Soc. People Plants Environ. 19(5):403-408. DOI: 10.11628/ksppe.2016.19.5.403

Kim, Y.H., S.G. Sohn, Y.S. Lee, H.S. Choi, and M.R. Huh. 2016b. Effect of the effluent waters from BFT inland aquaculture of the growth and fuctional substance contents in 3 types of vegetable crops. J. Korean Soc. People Plants Environ. 19(4):299-303. DOI: $10.11628 / \mathrm{ksppe} .2016 .19 .4 .299$

Kwon, T.E. 2014. Development and status of urban agriculture: focused on Nodeul garden. MS thesis, Korea Univ., Seoul, 
Korea.

Lee, D.G. and S.H. Cho. 2016. The analysis on the preference of urban agriculture types in accordance with lifestyle. J. Korean Institute Landsc. Architecture 44(6):40-50. DOI: 10.9715/KILA.2016.44.6.040

Lee, S.G. 2001. Pollution of aquaculture fisheries - Overcoming environmental problems in aquaculture farms, raising industrial cohesion. Fishing Port 57:30-34. Retrieved from http://www.riss.kr/link?id=A101530965

Lim, T.J., J.M. Park, J.S. Noh, S.E. Lee, and K.I. Kim. 2013. Effect of slurry composting bio filtration(SCB) by subsurface drip fertigation on cucumber (Cucumis sativus L.) yield and soil nitrogen distribution in greenhouse. Korean J. Soil. Sci. Fert. 46(4):253-259. DOI: 10.7745/KJSSF.2013.46.4.253

MLIT (Ministry of Land, Infrastructure and Transport). 2015. Statistics of urban planning. Retrived from http:// stat.molit.go.kr

Park, S.G. 2014, January 07. Good seeds change from farming methods to consumer tastes. The Farmers Newspaper, Retrieved from http://www.nongmin.com/article/ar_detail.htm?ar_id=227004\&subMenu=articletotal

Park, S.Y. 2016. Nutrient status of the soils used for urban agriculture in metropolitan city of Seoul. MS thesis, Univ. Seoul, Seoul, Korea.

Park, J.M., T.J. Lim, S.B. Kang, I.B. Lee, and Y.I. Kang. 2010. Effect of pig slurry fertigation on soil chemical properties and yield of tomato (Lycopersicon esculentum Mill). Korean J. Soil Sci. Fert. 43(5):488-493.

Ryoo, J.W. and W.K. Seo. 2008. Effects of concentrated pig slurry using membrane filter on the growth and yield of tomato in nutriculture. J. Livestock Housing Environ. 14(2):119-128.

Subramanianm, S., S.A. Mahali, and S.H.M. Taha. 1994. Red tide phenomena in Brunei-darussalam-some inplications for fisherise. Hydrobiologia 28:219-225. DOI: 10.1007/BF00005668

Zhou, D.M., X.Z. Hao, X.Z., Y.J. Wang, Y.H. Dong, and L. Cang. 2005. Copper and Zn uptake by radish and pakchoi as affected by application of livestock and poultry manures. Chemosphere 59(2):167-175. DOI: 10.1016/j.chemosphere. 2004.11.008. 